\title{
OS DISCURSOS SOBRE CIÊNCIA E SOCIEDADE: REFLEXÕES FILOSÓFICAS SOBRE A EDUCAÇÃO BRASILEIRA CONTEMPORÂNEA
}

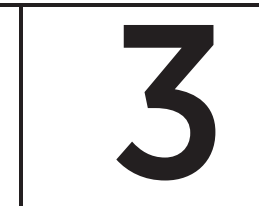

\section{THE DISCOURSES ABOUT SCIENCE AND SOCIETY: PHILOSOPHICAL REFLECTIONS ON CONTEMPORARY BRAZILIAN EDUCATION}

\author{
FERREIRA, Carlos Eduardo da Silva \\ Doutor e Mestre em Linguística e Língua Portuguesa pela Unesp/Araraquara \\ Doutorando em Multiunidades em Ensino de ciências e matemática na Unicamp \\ E-mail: karloseduardoo@yahoo.com.br \\ ORCID ID: https://orcid.org/0000-0002-6238-1983
}

\section{RESUMO:}

Este artigo trabalha centralmente com o texto de Geraldi (2003), 'Depois do show, como encontrar encantamento?' traçando, num movimento dialógico, a temática do fazer científico, tomando fios histórico-filosóficos sobre a ideia de ciência e sociedade. Para tal percurso, coloco em cena reflexões centrais de ópticas nietzschiana e bakhtiniana, apontando como os dizeres deste texto de Geraldi se aproximam destas bases de pensamento acerca de compreensões sobre o sujeito em seu trabalho científico a partir de concepções sobre ciência. Em seguida, estas reflexões desaguam em debates entremeados na esfera educacional a partir de uma análise discursiva em duas tirinhas retiradas da mídia do Facebook. Centralizo as questões sobre como encarar ciência e educação na contemporaneidade no que diz respeito à movimentação de identidades e sobre como as vivências escolares no cenário brasileiro vêm encarando a ideia de conflito e de devir em seus discursos oficiais. Temos, aqui, os "bastidores" do show que Geraldi nos encaminhou.

Palavras-chave: Geraldi. Bakhtin. Nietzsche. Ciência. educação brasileira. 


\begin{abstract}
:
This article works centrally with the text of Geraldi (2003), 'Depois do show, como encontrar encantamento?' ('After the show, how to find enchantment?') in a dialogical-dialectical movement, the theme of scientific development, taking historical-philosophical threads on the idea of science and society. For this course, I introduce central reflections of Nietzschean and Bakhtinian optics, pointing out how the words of Geraldi's text approach these bases of thought about understandings about the subject in his scientific work from conceptions about science. Then, these reflections flow into discussions in the sphere of education, after all, how to face science and education in the contemporary world with regard to the movement of identities? How have school experiences in the Brazilian scenario been facing the idea of conflict and becoming in their official speeches?
\end{abstract}

Keywords: Geraldi. Bakhtin. Nietzsche. make scientific. Brazilian education.

\title{
CIÊNCIA QUE TE QUERO! MAS, O QUE PODERIA SÊ-LA?
}

Abandonadas as certezas, sem âncoras, estamos forçados a pensar sem corrimãos que nos conduzam, porque não há um lugar a que chegar, não há um lugar em que ficar, não há um fim a alcançar. Por isso, talvez devamos retornar às perguntas fundamentais "que deveriam acompanhar-nos sempre como sinal de uma capacidade, essa sim, comum a todos os seres humanos: a capacidade que mantém viva a pergunta precisamente porque, sabendo que não há resposta, obriga-nos a continuar perguntando".

J.W. Geraldi

Quando se coloca o centro de gravidade da vida não na vida, mas no "além" - no nada -, tira-se da vida o seu centro de gravidade.

Nietzsche

Num texto 'controverso' aos outros do Cadernos de estudos linguísticos (44), Geraldi (2003) nos mostra uma publicação que reflete os ideais da nascida ciência moderna: o ponto de debate da ciência não 
buscava mais a essência ou a substância das coisas, mas sim a função; a pergunta não é mais "o que é?"; mas "como é?".

Este período, conhecido também como o Grande Racionalismo Clássico, provém de um ambiente que tenta vencer um grande pessimismo teórico, imperante no fim do século XVI e início do XVII: o ceticismo, uma atitude filosófica que põe em xeque a capacidade da razão humana para conhecer a realidade exterior na relação com o ser humano.

Chaui (2010, p.54) expõe:

As guerras de religião, as descobertas de outros povos diferentes dos europeus, as disputas e querelas filosóficas e teológicas criaram um ambiente em que o sábio já não podia admitir que a razão humana é capaz de conhecimento verdadeiro e que a verdade é universal e necessária. Ao contrário, diante da multiplicidade de opiniões em luta, o sábio tornou-se cético.

Para uma restauração de um ideal filosófico da possibilidade do conhecimento verdadeiro e universal, o Grande Racionalismo baseou-se em algumas mudanças teóricas:

- "surgimento do sujeito do conhecimento": a atitude científica de investigação deve partir não da natureza (como na filosofia antiga) nem de Deus (como na patrística e na escolástica) e sim da indagação da capacidade humana racional em demonstrar o conhecimento; o começo se dá pela reflexão;

- "as coisas exteriores (a natureza, as instituições sociais e políticas) são conhecidas quando o sujeito do conhecimento as representa intelectualmente" (CHAUI, 2010, p. 55). Tudo o que pode ser conhecido vem por conceitos representados pela clareza, pela demonstração, e natureza, sociedade e política podem ser inteiramente conhecidas pelo sujeito do conhecimento, pelo motivo da racionalidade;

- a "concepção da realidade como intrinsecamente racional e que pode ser plenamente captada pelas ideias e conceitos" (CHAUI, 2010, p. 55). Neste ponto, como é um sistema ordenado de causalidades físico-matemáticas pela razão humana, a realidade é racional. 
É no desenvolver destes planos reacionais em que a razão se presentifica cada vez mais na atitude científica que aparece o período das luzes - Iluminismo - trazendo consigo alguns posicionamentos epistemológicos idealistas, como:

- pela razão o homem vencerá as injustiças, conquistará a liberdade;

- a razão é capaz de gerar progresso, sendo o homem um ser perfectível;

Retomaremos esta questão.

Sobre a ideia da formação da base do conceito de ciência, analisemos dois textos inspirados na discussão da gênese científica:

A ciência é uma forma sistematicamente organizada do pensamento objetivo. (...) Da magia - considerada um conjunto de práticas destinado a aproveitar os poderes sobrenaturais - a ciência teria conservado uma aparência de mistério e gravidade ritual, traço que ainda hoje surpreende a maioria dos espíritos. Do feiticeiro ao cientista há apenas um pequeno passo, fácil de transpor, quando considerados os "milagres" da ciência moderna. Quanto mais escapam aos nossos sentidos as forças naturais das quais ela se aproveita (ondas hertzianas, eletricidade, emissões eletrônicas), mais parece ela realizar os sonhos dos mágicos. [...] A ciência, entretanto, apenas poderá ser magia aos olhos de espectadores, pois apenas se libertando da magia que a ciência propriamente dita pode desenvolver-se (GRANGER in CHAUI, 2010, p. 306).

Hoje, quase às vésperas da entrada gloriosa do século XXI, pouca gente, talvez, se dê conta de que a ciência já se apropriou do lugar outrora ocupado pela magia ou pela religião. A ciência é hoje a religião do homem moderno, que se considera 'iluminado'. Enquanto a tecnologia the fornece incessantemente novos inventos e engenhos 'milagrosos', a ficção científica mantém acesa a promessa de perspectivas cada vez melhores e mais incríveis, e a chamada literatura de divulgação - cada vez mais proeminente nos jornais e revistas de consumo em massa - cumpre a sua missão de levar aos quatro cantos do mundo a palavra da 'razão científica'. Tão inquestionável 
se tem tornado o prestígio da ciência entre os leigos nos dias de hoje que qualquer gesto que possa ser interpretado como uma ameaça a sua hegemonia corre o risco de ser taxado de blasfêmia, ou, no mínimo, submetido ao ridículo público (RAJAGOPALAN, 1991, p. 12).

Tanto um quanto outro texto expõe a ligação da gênese investigativa da ciência nos rumos do ideal mágico do estar no mundo. $\mathrm{Na}$ verdade, todo o questionamento humano provém de relações organizadoras/ordenadoras que tentam atribuir aos diversos fenômenos (físicos, químicos, biológicos, linguísticos...) uma espécie de explicação estabilizante dos conflitos de si: como eu, ser no mundo, invisto significado para os acontecimentos? Pensar na questão valorativa dos pontos de vista equivale a investigar questões profundamente arraigadas nos sujeitos e suas inter-relações, com ideologias em debate num lugar e num momento histórico, nas condições de circulação e interdição ou não de discursos nas diversas esferas sociais de interações. Tomar estes olhares significa, de modo investigativo, vislumbrar um ato ético, no que se refere a reflexão e refração de olhares de um sujeito-autorcoenunciador na dinâmica da arena que são os discursos, ou seja, é promover novos sentidos no entremeio das reverberações.

Numa dicotomia operacional entre senso comum $\mathbf{x}$ ciência desenvolveram-se passos que delimitariam um campo do outro e, além disso, pessoas que se delimitariam a cada um destes. Enquanto o senso comum é expresso em opiniões e sentimentos individuais, tende a uma análise qualitativa dos efeitos em nossos sentidos e desejos, é ora individualizante (pelos sentidos), ora generalizante (opinião sem ideia de passado transformador), tem vínculo com os hábitos, preconceitos, tradições cristalizadas, a atitude científica é objetiva, quantitativa, busca padronizações, é homogênea, generalizadora, é diferenciadora (não reúne por semelhanças aparentes, mas distingue iguais), apenas estabelece relações causais após investigações da natureza ou da estrutura do fato na relação com semelhantes e diferentes, surpreende-se com a regularidade, distingue-se da magia, é resultante de um trabalho dito racional.

Vem de Aristóteles a rigorosidade científica, como uma sistemática de ações. A definição de conhecimento científico para este filósofo está nas causas, isto é, numa relação de conhecimentos demonstrativos. A classificação aristotélica propunha os campos das ciências produtivas (além da própria ação; todas as atividades humanas que resultam num 
produto ou numa obra distintos do produtor: economia, arquitetura, medicina, teatro, oratória...), ciências práticas (práticas humanas como ações que têm nelas mesmas seu próprio fim: ética e política), ciências teoréticas ou contemplativas (aquelas que estudam coisas que não dependem dos homens e de suas ações), sendo estas subclassificadas em 1) ciência das coisas naturais submetidas à mudança ou ao devir (física, biologia, psicologia), 2) ciências das coisas naturais não submetidas à mudança ou ao devir (matemática, astronomia), 3) ciência da realidade pura (Filosofia Primeira ou metafísica) e 4) ciência das coisas divinas (teologia).

É nesta visão ocidental, digamos, que a ciência toma corpo: ao lado da sistematização filosófica. Sobre esta dinâmica, discorreremos mais à frente.

\section{CANTOS" \\ O PARTO DAS CIÊNCIAS HUMANAS: "FERIDAS, PROMESSAS E DESEN-}

O papel do trabalho do cientista dos dias de hoje sem dúvida não se limita à figura de laboratórios, jalecos e experimentos físico-químicos. A figura de Eistein nos lega facetas para interpretações de ser o cientista aquela personalidade profícua que terá que conversar com a 'magia do humano', que terá que largar a batina da natureza para se questionar: o que é o tempo e o espaço na relatividade? É a relativização de categoriais primordiais para existência humana que o trabalho científico - dito hard - no início do século XX toma em seu interior.

Bem verdade que já era um golpe que reluzia outros. O ser humano já havia sofrido pelo menos 3 grandes golpes:

- com Copérnico: não estamos no centro do universo; nosso planeta gira ao redor de uma estrela que se localiza numa galáxia de segunda instância; ela, a Terra, é um planeta pequeno e se localiza num terreno baldio de um universo que se dinamiza;

- com Darwin: não fomos feitos pelas mãos de um criador; descendemos de seres ancestrais;

- com Freud: não somos tão racionais; somos controlados por forças no qual não temos consciências;

Estes foram abalos que o orgulho do 'homem racional' sofreu; este homem caiu, como Ícaro e Dédalo, como Lúcifer. O homem vitruviano 
foi abalado; ele não representa o homem contemporâneo. O homem contemporâneo é aquele que não tem um lugar definido no universo. Ele é representado pelo quadro de Munch, em "O grito". Desmontaramse os sistemas metafísicos e as utopias sociais. $\mathrm{O}$ eu sujeito investigador contemporâneo teria que lidar com a diversidade da relatividade.

E falando sobre o trabalho dos cientistas, como podemos investigar objetivamente o objeto homem sendo que ao falar deste eu, cientista, pertenço ao conjunto destes seres? Afinal das contas, como ser quando não se é subjetivo (sujeito + objeto)?

Embora evidente que qualquer ciência é humana, pois vem de atividades humanas de conhecimento, o termo "ciências humanas" designa as ciências que possuem o próprio ser humano como objeto de análise. A situação dessas ciências configura arranjos especiais.

Primeiramente porque a colocação do homem como objeto de estudo científico é um foco engendrado somente no século XIX. Até este ponto, cabia à Filosofia tudo quanto se referenciava ao humano.

Pelo motivo de surgirem após as ciências matemáticas e naturais serem empregadas como definição para um ideal de cientificidade, metodologia e conhecimento científico, as humanidades, como processo/ grupo amplo científico, tenderam - forçosamente - a "imitar" e copiar o paradigma estrutural-metodológico que aquelas ciências haviam postulado, estudando o homem como objeto natural - no sentido de natureza -, matematizado e experimental. Dessa maneira, "para ganhar respeitabilidade científica, as disciplinas conhecidas como ciências humanas procuraram estudar seu objeto empregando conceito, métodos e técnicas propostos pelas ciências da natureza" (CHAUI, 2010, p. 312).

\section{O SHOW...}

No decorrer de seu texto, Geraldi (2003) vai explanando o desenvolvimento da pesquisa científica no plano moderno, idealista, iluminista, racionalista.

O movimento racionalista do esclarecimento - período das luzes, iluminista - se apresentava como a possibilidade de emancipação do gênero humano pelo intelecto. Com o desenvolvimento e progresso da razão, pela ciência e pela técnica, é que o homem se colocaria em condições de resolver todos seus problemas. É pela dominação da natureza externa e interna... 
Assim, humanizar a natureza, naturalizar os processos humano serão paridades que elevariam moral e politicamente a 'sociedade humana'. Instaura aqui a ideia de futuro promissor: é no futuro que ocorrerá a bem aventurança, a seguridade, a prosperidade, a salvação.

Nesta transição paradigmática em que a Idade Média está deixando de existir para assim se revelar um novo momento histórico - a Idade Moderna - e um novo momento para a filosofia - a Filosofia moderna - encontramos, logo no início do século XVII, dois grandes expoentes: Descartes, filósofo francês autor de $O$ discurso do método, dirá neste livro "Nós, seres humanos, senhores e possuidores da natureza" e Bacon, pensador inglês, escreverá sua célebre frase: 'Saber é poder'.

Isso significa que o homem se vê capaz de dominar todo o seu redor; se vê capaz de dominar as forças da natureza física e a dinâmica dele mesmo. O homem muda sua imagem e se vê agora dotado de liberdade, iniciativa e de um enorme poder criação.

Há aqui um reforço e fortalecimento das dualidades, das dicotomias advindas do modelo idealista. O homem deixa de ser um todo, torna-se um ser dividido. Divisões como corpo/alma; terra/céu; mundo/homem; divino/humano; sobrenatural/natural; cultura/natureza; consciência/ instintos; razões/paixões; vida/morte.

Fiat lux! - Faça-se a luz!

Sapere audi - coragem de servir-se a própria inteligência (Kant).]

A natureza do objeto humano foi, decerto, dotada de um descrédito, porém seria este o paradigma para o progresso: a iluminação via racionalidade. Mesmo com o reconhecido estado da duplicidade do homem - ser ao mesmo tempo corpo e alma, extensão e consciência -, Descartes instaurou/realojou a separação entre matéria e pensamento. Desta forma, o sujeito consciente se opõe ao objeto, perante aquilo que se é conhecido. É com ele, Descartes, que se delimita a fundação de uma Filosofia do Eu ou Filosofia do sujeito, segundo a qual o conhecimento é entendido como fonte originária de elaborações individuais. Assim, o que o pensamento de Descartes desempenha é retomada do modelo racionalista, cuja fonte alude a Platão e que toma por base que o saber tem origem na razão, está a antecedente e explicadora de todo o real.

Nota-se que estamos diante de um modelo milenar calcado na separação de sujeito e objeto. Será que o paradigma racionalista trouxe uma aproximação do humano ou uma objetificação do sujeito? podemos falar em sujeitos?

Após as feridades causadas pela racionalidade, e caídas as certezas, vemos que o show da iluminação racional sobre o todo - que era 
cindido - obtém seus questionamentos, resultando hoje na prerrogativa: em que medida um processo cultural quando ele se realiza e esgota acaba por extrair as últimas consequências da sua dinâmica e dos seus próprios valores? Tendo libertado o homem de seu longo e tenebroso sono - como chegou a imaginar o filósofo alemão Immanuel Kant -, o lluminismo fez com que ele começasse a sonhar novamente, só que, dessa vez, acordado. Acordamos, porém, na pós-modernidade assim como quem desperta num pesadelo cujo cenário é uma torre muito alta que balança ao sabor da fúria dos elementos naturais. Das alturas de nossa incerta ascensão contemplamos o abismo do futuro: o que levar para essa queda? O que conservar? Do que desistir?

Geraldi (2003) trata deste despertar a fórceps. Como interpretar a ideia de futuro perante um mundo instável nas relações? O homem pós-moderno é este que as luzes intensas do iluminismo o deixaram ludibriado, cego de tanta luminosidade, caminhando incerto sobre uma fina casca de gelo - como expõe Bauman ${ }^{1}$-, se pararmos, ela racha; e continuamos num caminhar incerto.

Para Bauman, a consciência pós-moderna antes de tudo é a consciência do fracasso, do fracasso da modernidade. Ela fracassou nas utopias que prometeu a si. A modernidade se caracterizou pela utopia da vida científica. Numa dialética filosófica permeada pela moral, estamos diante de uma nova humanidade criada pelas tecnologias naturais, sociais e políticas. No horizonte, o imperativo do progresso e sua asfixia niilista. É um despertar maldito dos sonhos gloriosos para uma espécie de pesadelo cotidiano, porém com um investimento de esperanças.

Precisamos nos preparar para uma "ética para o inverno", à la Bauman, mesmo estando em primaveras sociais.

A eficácia e o resolver rapidamente os problemas estão em jogo. Não há tempo! O metaparadigma da alta velocidade nos encerra: há uma necessidade de instalação de uma consciência pós-moderna. Como andam nossos relacionamentos? Como está nossa ideia de formação pessoal? Será que o máximo de identidade que estamos tendo é o estilo, isto por causa de uma espécie de apagamento de julgamentos éticos?

A instabilidade nos é mostrada pelo conjunto de ações e saberes. Como lidar com o caos se somos bombardeados por formações que não dão conta de discursos da vida?

1 Célebre uso por Bauman. Advém de uma paráfrase de Ralph Waldo Emerson (poeta e filósofo americano do século XIX) no sentido de estarmos vivemos como se estivéssemos atravessamos o inverno, numa casca fina: se andarmos devagar o chão racha. 


\section{HORA DE FAZER UM SHOW DO ABSURDO: NOVOS MODELOS}

Retomando a discussão a respeito da noção de futuro, da ideia do conflito do homem perante o mundo e acerca do modelo de pensamento idealista é Nietzsche quem convoco para tomarmos uma reflexão sobre a transformação do processo da racionalidade.

Por que atentarmos em Nietzsche? Ora, é inegável seu percurso analítico sobre a transvaloração de todos os valores, em muitas vezes com certa aversão à contemplação mórbida de história da Filosofia (para a época). Trago Nietzsche para nos ajudar a discutir a ideia de futuro atrelada a posicionamentos eleitos num período do presente.

Dialogando explicitamente com Nietzsche na consciência de sermos "humanos, demasiadamente humanos", Geraldi (2003) atualiza algumas questões centrais dos questionamentos do filósofo alemão; a própria abordagem sobre a discussão de uma atuação ética, identitária, construinte no enfrentamento da instabilidade do movimento (ONDE ENCONTRAR ENCANTAMENTO?) é bastante cara a Nietzsche.

Coloquemo-nos em alguns pontos para irmos desenvolvendo nossa reflexão:

\section{IDEIA DE FUTURO}

O assentamento da racionalidade se colocava num amplo paradigma de busca da verdade. A verdade de cada ser era aqui, de algum modo, a procura filosófica de uma realidade estável, configurada no paradigma do alcance do domínio do humano por todas as variáveis do mundo e de si. Para Nietzsche, a história do conhecimento humano é a história da criação e da cristalização da verdade. Deste modo, o questionamento era focado nas perspectivas de modo que houvesse perguntas como: quem tem a verdade? É Espinosa? É o cartesianismo? É o empirismo? Onde está o rumo? Pois Nietzsche toma, de modo artístico, um posicionamento outro: para que e por que a verdade?

Para Nietzsche, avesso a uma tradição idealista de busca $\mathrm{d} A$ verdade, o homem que se supera está na invenção de si, não nos moldes de uma tal verdade.

Para o filósofo, a história do pensamento humano ocidental é uma ilusão, pois fincava sua construção em um modelo humano inalcançável: o idealismo socrático-platônico. Nietzsche vai dialogar com o período anterior a este ponto fundante do racionalismo filosófico. Ele se relacionará com a Grécia arcaica, onde o pensamento marcado pela arte, pela intensidade da vida, em que o desconhecimento da vida é um fator 
inerentemente intenso, se posiciona de modo que a movimentação das coisas, dos seres, do mundo é o centro das discussões, ora confirmado, ora rejeitado, mas central. Impensável neste modelo de pensamento, digamos, que o homem domine as forças da natureza e da vida. O devir, este instante presente grávido de sentidos, é relido por Nietzsche de forma a mostrar a radical mudança condicionada pelo modelo socráticoplatônico.

A configuração de que a ideia é superior ao corpo; a negação do corpo; a crença de que há um 'mundo' além deste, dominado pelas ideias, pela verdade; a interpretação de que as sensações desta vida levam ao erro; a negação do hic et nunc (aqui e agora); a desvalorização da contradição e do conflito; a negação de tudo que se transforma; e construção de uma imagem idealizada de si mesmo e do outro são formas manifestas do modelo imperante da discussão nietzschiana. Segundo Nietzsche, o pensamento socrático-platônico matou o devir. Outro ponto a ressaltar nas discussões nietzschianas é que, na Idade Média, aquilo que Platão construiu como pensamento, o cristianismo ratificou como religião. Assim, esta vida seria um erro, o corpo também seria - o pecado original -, o pensamento puro é um 'outro', de um outro 'lugar'/mundo, e não este desta nossa existência. Postula o cristianismo, neste sentido, uma negação desta vida em nome de uma outra.

Pois é neste "apregoamento" de ideal futuro que Nietzsche embate seus dizeres. A idealização do futuro, para ele, é um aniquilamento do presente, é apagar o instante do devir.

\section{MORTE DE DEUS}

Ao contrário de uma interpretação sobre este dizer que coloca em Nietzsche a ação de matar, exterminar a figura do deus cristão, quem mata Deus, ao ver nietzschiano, é a própria ciência, as novas formas de se saber e de se entender a vida, a si.

Com o nascimento da ciência (moderna) não se quer esperar a morte. Há aqui uma política de biopoder - como desenvolve Foucault em suas reflexões ${ }^{2}$. Afasta-se a morte de si pelo conhecimento de fatos como os sinais corporais dela; as lições de anatomopatologia lançam novos saberes em que os órgãos são fontes semiológicas.

BIOPODER: Esse assunto está relacionado às técnicas de sujeição dos corpos e do controle das populações dos tempos modernos. Em oposição à tanatopolítica, cálculo que o poder faz sobre a morte, está a biopolítica. No tocante à história das relações intersubjetivas, Foucault demarca a passagem de um poder de dominação sobre o outro, sobre a administração da vida e da morte do outro a um poder relacionado ao controle das práticas dos sujeitos pelo gerenciamento das instituições, ao modo do que os sujeitos fazem de sua vida em todo plenitude. História da sexualidade I - A vontade de saber. 
Ao ter uma dor de dente não se recorre mais ao poder exclusivo do Todo Poderoso. No lugar do trono do deus Salvador coloca-se a figura do cientista.

Matar deus, assim, não é expor um atestado de óbito das honras e glórias a uma entidade/força. As pessoas não necessariamente deixaram de acreditar na divindade, de ir às igrejas, de falar nele, mas vivem, segundo Nietzsche, no túmulo do deus morto, na sombra de Buda ${ }^{3}$. A presença de Deus na modernidade já não é intensa como fonte suprema de consulta, como em tempos anteriores, mas está ligada a uma ação mediadora com a vida ou como signo: um pedido, uma promessa.

\section{NIILISMO}

Configura-se o niilismo o posicionamento de que os valores superiores perdem a atuação nas práticas do dia a dia. Analisando com mais atenção percebemos que o fundamento do niilismo é a negação. É o nihil, termo latino correspondente ao nada; porém é um nada negante a organizações vigentes; é um nada antes de tudo reacionário.

Posicionemos em nossa reflexão dois tipos de niilismo:

- o niilismo platônico-cristão, de crítica nietzschiana, onde há uma negação de tudo (do mundo, das vivências) em nome de uma vida outra, verdadeira;

- o niilismo da modernidade, baseado na crítica de Deleuze, onde há uma reação a Deus e no lugar do Seu trono de deus Todo Salvador é colocada a figura do cientista.

Tanto o niilismo negativo quanto o niilismo reativo é abdicada a ideia da potencialidade do presente em nome de um ideal de futuro. Pois se antes eu não vivia o presente em nome de um paraíso, hoje não vivo o presente por um ideal de progresso, por uma noção positivista de preparação de um futuro não meu, mas para descendentes: é uma anulação de mim (si) em favor de um ideal posterior, não este. E é em este cenário que as relações de vivência têm fundamentado as práticas morais.

\section{IDEALISMO}

Para Nietzsche todo idealismo é uma espécie de niilismo, já que há valores superiores e estes restritos a um verdadeiro modo de se agir,

3 Em A gaia ciência, Nietzsche dirá: "Lutas novas. - Depois da morte de Buda sua sombra ainda se mostrou durante séculos numa caverna; sombra enorme e aterradora. Deus morreu, mas os homens são de tal modo que haverá ainda, talvez, cavernas nas quais sua sombra se mostrará (2002, p. 121)". 
uma filosofia que parte de um mundo pré-concebido, não vivido, nem experimentado, nem ressignificado. Em sua obra Miscelânea de opiniões e sentença encontramos: "O idealista é incorrigível: se é expulso do seu céu, faz um ideal do seu inferno".

Isto se dá por que o ideal não tem as transformações que o acontecimento tem.

\section{TRANSVALORAÇÃO}

Tendo criticado Nietzsche essa postura central idealistadespresencial do modelo padrão do pensamento ocidental em que a ideia de futuro tira o homem tempo e do conflito, do devir, a resposta nietzschiana para tais atitudes se posiciona na busca da superação do homem pelo/no presente. Necessita o homem ter coragem para a lida (super-homem nietzschiano). O presente é o instante supremo da capacidade de ver a si mesmo, de compreender a si mesmo. O presente é o momento grávido das atuações, é a confluência do passado com a projeção futura. É o momento da exposição da emergência, dos caminhos possíveis, do erro, do acerto, da movimentação de si e do outro... da vida como complexidade humana.

O que Nietzsche configura com a discussão da transvaloração é uma quebra de um processo e de um modelo que contribuíram com questões que fundamentaram uma constituição de uma sociedade excludente, desigual; uma sociedade que colocou em evidência o ideal constituinte na estabilização e repetição de uma negação da movimentação. "É necessário ter o caos cá dentro para gerar uma estrela".

Geraldi (2003) pontua: "estamos condenados a sermos cada um o herói de sua própria vida: valores morais como a autenticidade, a sinceridade e a adequação consigo próprio exigem comportamentos, ditam modos de ser e exigem que respondamos pelo lugar que ocupamos" (p. 256).

\section{CAOS}

Se o presente fora negado ou em nome lugar outro da vida verdadeira ou por um ideal de progresso, pela transvaloração, por um caráter explosivo do pensamento encara-se, a partir de conceitos sobre caos, como um momento fértil desestabilizante de relações intersubjetivas, intrasubjetiva. Esse impasse perante a novidade de cada presente impulsiona para a ação, para o movimento, para o diferente, para o outro (animado/inanimado) na busca de definição de si próprio. $\mathrm{O}$ 
caos mobiliza atitudes para possíveis organizações, para estabilizações. Essa determinação, definição ou identidade do homem são construídas por meio de sucessivos diálogos internos (consigo próprio) e externos (com o outro). O caos pertence, assim, à ordem da dinamicidade, dos processos interacionais grávidos de sentidos.

Quando os futuros são incertos, porque não seguem uma lei ou uma ordem, todas as possibilidades são imagináveis. Abramos os braços para os abraços desta nova aprendizagem.

\section{EGIPCIANISMO}

Configura-se egipcianismo a crítica radical que Nietzsche estabelece com a história da racionalidade ocidental, baseada na segmentação, no isolamento de uma determinada questão de discussão, como num caráter de mumificar o conhecimento e as práticas dos saberes deste.

Nietzsche discute sobre a necessidade de se ter a perspectiva explosiva do pensamento para que questões da vida estejam presentes/ presentificadas. Sua crítica é feroz a respeito da História da Filosofia. Ele se posiciona, como já discutimos, que a história do conhecimento humano é a história da criação e da cristalização da verdade, numa "renovação" por revezamento de bastões a uma tendência museificada (de museu). Nietzsche chega a traçar uma linha dicotômica diferenciando filósofos, os que lidam com a potencialidade do caráter explosivo do pensamento, com o que chamou de trabalhadores científicos ou operários, os eruditos ou preocupados na labuta da história do conhecimento; chega a designar Descartes e Kant neste último campo.

O que podemos focar nestas linhas reflexivas que traçamos são as críticas nietzschianas à negação do que é a vida como vivência, experimentação, aprofundamento de si na relação ética. É necessária uma crítica aos valores históricos cristalizados. Mais atual do que nunca, a discussão dos conceitos nietzschianos nos põe em questão o olhar de como atuar perante a diversidade, a diferença diante de uma nem tão 'nova ordem mundial'. Como está nossa relação entre modelo e ressignificação? Entre teoria e prática? Entre eu e outro?

Jair Ferreira dos Santos (2005, p. 78) sintetiza em três conceitos e/ou valores ocidentais os desmascaramentos postos pela crítica desconstrutiva nietzschiana: Fim, Unidade, Verdade:

Fim, Unidade e Verdade e sua valorização, desvalorização e transvaloração. Com isso, Nietzsche está abalando 
três pilares da cultura ocidental: cristianismo (Fim), o conhecimento científico (Unidade) e a Razão filosófica e moral (Verdade). A pós-modernidade é o momento em que tais valores, ainda atentos e fortes durante a modernidade industrial, entram em decadência acelerada. Se isso cai dar ou não na transvaloração, no Super-Homem, é outro papo.

Podemos fazer um paralelo ao que Geraldi (2003) coloca como "desconstrução das três características básicas que as introduziram como substitutas dos objetos de nossas crenças" (p. 253): a universalidade, baseada no Fim; a objetividade, na concordância com a Unidade; e a preditibilidade como princípio da Verdade. Todas estas postas em xeque. Lidamos com "acasos e possibilidades" em instâncias do instável, em estáveis provisórios.

Façamos um momento do outro papo pensando num exercício de análise a discussão de como podemos conceber a ideia de conflito e devir na esfera escolar-científica.

\section{IDADES}

\section{A ESCOLA COMO LUGAR FUNDANTE: SUJEITOS EM SUAS DISCURSIV-}

Por que focar na escola? A escola é a instituição na qual se delega o poder da formação dos sujeitos em nosso universo cultural letrado. Os discursos ali circulados mobilizam tramas avaliativas, ou melhor, refletem como as ideologias estão sendo materializadas nas ações de cada sujeito envolvido, projetando modos de se entender a vida, modos de entender relacionamentos subjetivos e intersubjetivos, de confrontar moral e ética. Investigar dialeticamente os discursos escolares, em primeira instância, é lidar com uma genealogia de formações dos sujeitos e reverberações do que se espera da vida em sociedade.

O estudo sobre sujeito em Bakhtin propõe que um sujeito não só é histórico, social, ideológico, mas também corpo, vivência (BRAIT, 1999). Tem-se um sujeito construído pela linguagem, pelo "outro", com uma construção de si mesmo pelas experiências de olhares de "outros", em divergências e convergências. Em Bakhtin, o sujeito possui um projeto de dizer que não depende apenas de sua intenção, mas sim de um "outro (primeiramente é o "outro" com quem fala, depois o "outro" ideológico, tecido por variedades de discursos do contexto) e, ao mesmo tempo, o sujeito é corpo. De acordo com Compagnon (apud BRAIT, 1996), toda enunciação produz simultaneamente um enunciado e um sujeito; não há sujeito anterior à enunciação ou à escritura. A enunciação é constitutiva 
do sujeito, e este advém da enunciação para se posicionar, se referenciar, ancorar.

A constituição de sujeito para Bakhtin se dá por meio da interação e (re)produção nos seus dizeres, revalorizando interpretações, e na sua práxis do contexto imediato e social. Segundo ele, a "consciência individual não só nada pode explicar, mas, ao contrário, deve ela própria ser explicada a partir do meio ideológico e social. A consciência individual é um fato sócio-ideológico." (BAKHTIN, 1992, p. 35). Tem-se aqui a noção de construção de sentidos em que para se produzir um sentido, deve-se haver uma compreensão na situação, no dentro (texto) e no fora (história).

Toda essa trama de dizeres que constituem os sujeitos liga-se a que Bakhtin denomina diálogo. Tomemos que com Bakhtin o dialogismo é o cerne da constituição do sujeito, inclusive do conhecimento no campo das Ciências Humanas. Sendo assim, não há um único ser humano cuja condição de humanidade não advenha da sua interlocução com os demais, posto que sua existência é dotada de significados anteriormente predicados e marcada pelo modo como um se posicionará na continuidade a essa interlocução.

O "sujeito da compreensão não pode excluir a possibilidade de mudança e até de renúncia aos seus pontos de vista e posições já prontos. No ato de compreensão desenvolve-se uma luta cujo resultado é a mudança mútua e o enriquecimento" (BAKHTIN, 2003, p. 378).

Compreender sujeito pela perspectiva dialético-dialógica bakhtiniana é ler o mundo, é "enfrentar o problema de construir, no fluxo das instabilidades, uma estabilidade, e confessá-la ao Outro como uma posição provisória que permite propor a hipótese" (GERALDI, 2003, p. 259).

Podemos analisar que a noção de leitura utilizada por Geraldi neste trecho não diz respeito apenas à atividade escrita, mas sim a uma atividade maior, global, de posicionamento de si na relação com o Outro, numa leitura de mundo(s). O fluxo do devir propõe uma cadeia de famílias parafrásticas de atos. A provisoriedade é um estabelecimento fundante para a perspectiva dialógica, em que a constituição de si e do outro se dá na relação radical de grau de experiências.

Marchezan (2008) assim nos coloca a respeito do emprego da Análise Dialógica do Discurso (ADD) como "óculos" teórico:

$\mathrm{Na}$ perspectiva bakhtiniana, buscar a compreensão das "formas concretas dos textos" (do discurso, do enunciado), 
que ocorrem em condições dialógicas, que não são naturais, imprevistas, mas, sim, sociais, históricas, é alcançar também o homem, a sociedade que o constitui e é constituída por ele. Tal como o homem, o texto é complexo, heterogêneo; dele ressoam vozes sociais diversas, que se apóiam, que se debatem. Reiteração de outras vozes já conhecidas, o texto é, ao mesmo tempo, uma voz única e irreproduzível. E é essa singularidade mesma que explica sua existência, seu acontecimento (p. 6).

Nestes dizeres percebemos como a ADD orienta na interpretação textual (em sentido extenso), numa construção de sentidos articulada pela história e a sociedade que o produziu, possuindo nestes dois pontos - linguístico e histórico - um posicionamento analítico para a construção do ser humano, em si e com o outro.

Ter o dialogismo e a alteridade como marcas das relações estabelecidas no contexto da pesquisa significa, portanto, buscar o encontro com o outro e compartilhar experiências, reflexões e valores que se alteram mutuamente. Sendo assim, nesta abordagem teórica, o outro deixa de ser uma realidade abstrata a ser definida e traduzida por um conceito. Em outras palavras, o sujeito da pesquisa é visto como alguém cuja palavra se confronta com a do pesquisador, refratando-a e exigindo-lhe resposta. Em contrapartida, a palavra do pesquisador recusa-se a assumir a aura de neutralidade imposta pelo método e integra-se à vida, participando das relações e das experiências, muitas vezes contraditórias, que o encontro com o outro proporciona.

Encaminhemos, agora, reflexões a fim de trazer um diálogo entre ciência e educação na contemporaneidade. Como estes lugares ideológicos se colocam no que diz respeito à movimentação de identidades dos sujeitos? Como conceber a ideia de conflito, de devir nas práticas discursivas escolares?

Por meio destas discussões bakhtinianas sobre a linguagem e por meio das singularidades das situações de ensino presentificadas no horizonte de quem se propõe a pensá-lo que percorreremos uma esta análise/discussão da escola brasileira contemporânea.

\section{ANÁLISES: OPORTUNIDADES DE DISCUSSÕES}

Temos as seguintes questões como ponto de partida: como estas discussões histórico-filosóficas atreladas a análises linguístico-discursivas podem auxiliar numa construção de aula/escola que tome o sujeito como 
aprendente-atuante? Como conceber a aula como um acontecimento?

Façamos, num processo dialógico, uma reflexão sobre a noção de base epistemológica da escola brasileira contemporânea, dialogando os conceitos e discussões que viemos digladiando até agora.

Começo com uma citação de Geraldi (2003):

É necessário apontar para os não-equilíbrios sociais para explorar as novas possibilidades de nos darmos regulamentações outras, em que o paradoxo da liberdade individual se complemente pela responsabilidade da coexistência. Experimentar novos caminhos, sem exigir que já estejam prontos antes de serem percorridos é aceitar toda ação como uma aposta (p. 257).

A constatação de que o ensino escolar não está suprindo os requisitos da sociedade atual, precisando, assim, de reformulações e mudanças, fez com que Isabel Alarcão (2001) e seus colaboradores lançassem uma planificação de uma escola reflexiva, em analogia ao que Nóvoa (1995) e Schön (1998) chamaram de professor reflexivo.

Esta concepção educacional considera a escola um organismo em vida, em desenvolvimentos nas atuações de suas práticas, norteada pelo fim de educar.

Tomo como processo dialético trazer alguns pontos que ajudem a discutir a constituição de um modelo escolar vigente na contemporaneidade brasileira.

A escola, como instituição, reverbera, além de inúmeros outros discursos, questões que fundamentaram uma constituição de sociedade.

Os desafios da escola não se constituem apenas neste espaço social, porém trilharei a minhas reflexões no entorno de modelos escolares vinculados a ela.

Quero focar nas práticas constituintes do modelo escolar contemporâneo brasileiro e pensarei, para tal caminho, como a noção de instabilidade não se configura como prática atuante na relação teoriaprática.

Elejo duas tirinhas retiradas da mídia Facebook para refletir, num processo dialógico, sobre a noção de base epistemológica da escola brasileira contemporânea, dialogando os conceitos e discussões que viemos digladiando até agora. Sendo textos em circulação podemos analisar como este material verbo-visual pode nos trazer questões sobre a situação vivencial da escola contemporânea brasileira por meio da materialização das ideologias nos discursos. 
São as tirinhas:

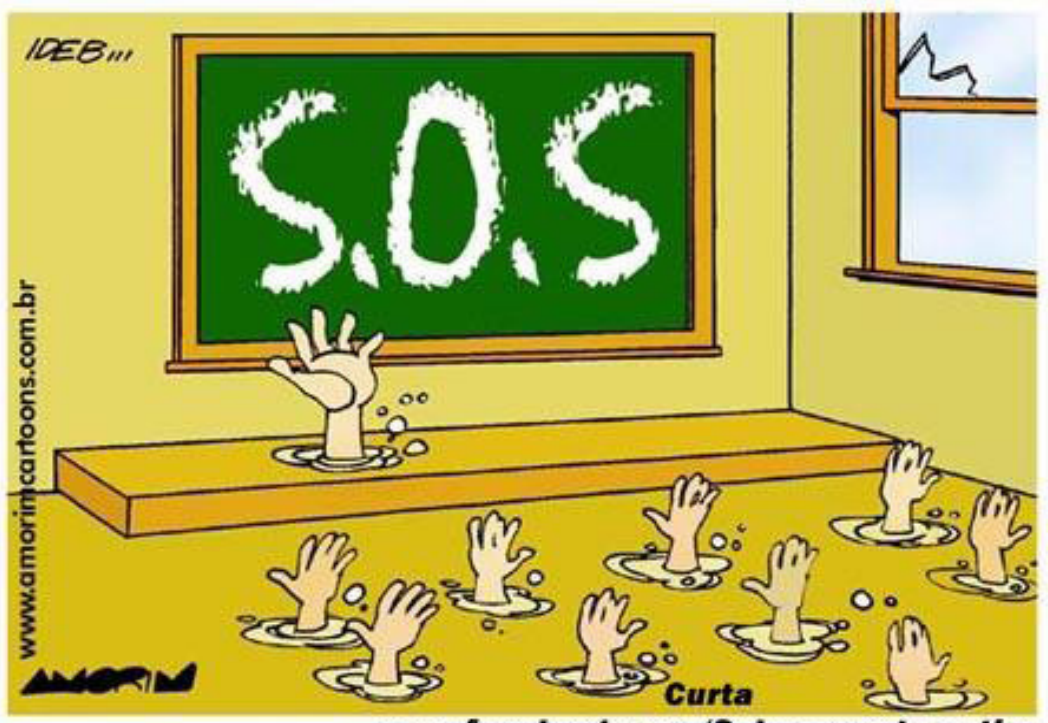

www.facebook.com/Solucaomatematica

Figura 1: Tirinha retirada do Facebook

Fonte:https://www.facebook.com/photo.php?fbid=765158720353678\&set=a.10402749980 0140.1073741830.100005786702879\&type=3\&theater. Acesso em: 3 abr. 2018.

A tirinha nos remonta a um espaço escolar disfórico, necessitado de ajuda, como a marca S.O.S nos mostra. É um S.O.S como sinal típico de socorro ao mesmo tempo evidenciando uma leitura de abandono: a sonoridade evidencia 'sós'. A janela quebrada nos proporciona uma leitura de que há algo para ser concertado, pois algo está desajustado; o fechamento da imagem num espaço entre quatro paredes evidencia a compartimentarização do ensino, já que a escola se configura em ensinar; o quadro negro escrito a giz pode nos remeter um sentido de atraso tecnológico; a submersão dos sujeitos indica também um pedido de socorro: ao mesmo tempo que os braços estendidos revelam uma prática escolar de ordem - ergue-se o braço para se perguntar algo -, este mesmo sinal é ressignificado num pedido de ajuda a um afogamento, afogamento este que remete a uma ideia de sufoco; o que é este líquidosólido que afoga os sujeitos da cena? É aquilo que não condiciona a manutenção da vida, aquilo que o IDEB - Índice de Desenvolvimento da Escola Básica -, um instrumento político-econômico da escola básica pública, está revelando: a precariedade do espaço escolar. 
Ademais desta crítica ao descaso com a (infra)estrutura escolar que também chega a ser uma crítica ao descaso com os sujeitos ali envolvidos, chamo atenção a alguns elementos que evidenciam práticas escolares.

Mesmo tendo todos afogados na precariedade, podemos perceber que há uma hierarquização inerente a este espaço. Há uma mão maior em cima de um tablado que se posiciona verticalmente, impondo um referencial a ser tomado, como se fosse um ideal a ser copiado, seguido, além de este se mostrar superior aos demais que se presentificam ali. Esta caracterização está revestida na imagem do professor, pessoa esta que é apenas um papel social em cumprimento.

$\mathrm{Na}$ percepção desta constituinte de sala de aula como artificialização laboratorial para a vida (?) está também estabelecido o ideal de homogeneização da classe do alunado. Não há mãos negras, verdes, rosa, azuis... o que há são mãos monocromáticas. Esse aspecto cromático da materialidade reflete o entendimento operante das práticas escolares: a massificação e o apagamento da diversidade; a coletividade ganha espaço para uma homogeneidade de agires. Será mesmo que a escola está retratando a vida?

Nesta configuração, podemos refletir sobre um modelo constitutivo na escola brasileira baseado por características advindas das práticas industriais.

Com a necessidade da ampliação da 'mão de obra' condicionada pela Revolução Industrial Tardia ${ }^{4}$ no Brasil, década de 70 do século XX, houve um boom no aparecimento de escolas pelo território brasileiro. Era necessário ter lugares de formação para que cada indivíduo soubesse minimamente ler, escrever e operacionar raciocínios para esta nova demanda nacional em surgimento. Nasce então a chamada escola de massa, em que temos o lema governamental "A escola agora é para todos". Temos aqui uma matriz fundante de um modelo educacional: a escola como reflexo da indústria. Este será um modelo para as constituições das práticas escolares. O que há aqui é tanto um entendimento estrutural escolar ao ambiente da fábrica quanto uma prática de ações de formação entendidas como uma montagem linear fordista, delegando à escola propriedades como montar séries escolares de pessoas - temos $1^{\text {a }}$ série, $2^{a}$ série, que agora, recentemente, substitui-se este termo por ano, assim temos $2^{\circ}$ ano, $3^{\circ}$ ano, porém numa mesma configuração estrutural de se entender o processo escolar; de compartimentar as temáticas envolvidas

4 Tardia em relação aos outros países. Cabe-se uma crítica aqui à questão de incorporação de tecnologias desgastadas ou ultrapassadas das potências econômicas. 
numa fragmentação do processo, pois temos pessoas especializadas em resolver questões referentes à Matemática, à Biologia, à Língua Portuguesa mostrando uma separatibilidade do processo formativo; de linearizar o ensino como passo a passo, configurando um cenário de aprendizagem não sistemático, não relacional, não interdisciplinar em si, como base geradora; de produzir alunos em larga escala e em curto espaço de tempo, objetivando um foco na abordagem quantitativa de seus formandos; de padronizar um aluno e um conteúdo ideais como referência a ser seguida/adotada, ou seja, há uma reprodutibilidade tecnicista; sem falar, mas já comentando, a questão do sinal sonoro presente como indicador de limite de tempo: o sinal sonoro estabelece a demanda temporal de atuações que uma esteira tem para produzir. A escola aqui configurada traz paralelos a uma linha de montagem que, ao final de um processo, produz um material objetificado; temos, assim, uma clara objetificação dos sujeitos nesta linha de montagem institucionalizada.

A tirinha assim faz, nessa linha analítica, alusão a um fenômeno marcante na realidade contemporânea: a questão da produção cultural "industrializada", massificada e alienante. Está aí uma utilização fetichizadora da escola a serviço de interesses ideológica e politicamente identificados - que não se relacionam com crítica cultural, em suas variadas formas de expressão.

O que caracteriza este modelo escolar industrial é a fragmentação e a segmentação, uma falta de noção de um todo. Não há sujeitos, há indivíduos dotados por uma superficialidade de papéis sociais a serem cumpridos. Onde se reserva o espaço da reflexão, da inovação, da tomada crítica de si por si mesmo? Como pensar ética neste espaço?

Seguindo nossa análise/reflexão, podemos firmar como base outra influência constitutiva da escola brasileira: a escola como reformatório, como uma prisão.

Advinda de condições concomitantes ao modelo industrial, a escola de modelo prisional se caracteriza centralmente na ideia de passivização dos sujeitos atrelada à ideia rigorosa de disciplina, de obediência unilateral, de reprodutibilidade de ordens, modelos, exemplos. É válido ressaltar que as condições histórico-sociais brasileiras neste período do boom da Revolução Industrial Tardia no Brasil estão ligadas à Ditadura político-moral na qual as figuras do poder eram generais, cargos atrelados ao Exército, aos aparelhos repressivos do Estado. 
A tirinha em análise delineia uma hierarquia - professor/alunos - pela disposição vertical, a fim de controle dos sujeitos-alunos, estes vistos de forma homogeneizada, hierarquicamente inferior, disciplinados em seus corpos e mentes.

Com a análise de alguns nomes atribuídos à estruturação escolar podemos inferir relações para discutir as práticas escolares.

O nome do currículo escolar conteudístico é denominado grade, que é formado por disciplinas; há um processo avaliativo que é chamado de prova, ou seja, há uma necessidade de provar algo: quer dizer então que os sujeitos chegam condenados e precisam defender a si; há pátios em que os sujeitos vão ter momento de recreação; pátios estes que são vigiados por inspetores.

A necessidade de construção deste espaço escolar diz respeito a uma necessidade ou desejo da sociedade vigente de produzir passividade; e disciplinarização dos corpos para uma ausência de questionamento e criticismo atrelada a ações de repetição, e não uma explicitação de recriações de um conteúdo.

Se a escola é um espaço isolado, fragmentado, segmentado, com uma implicação hierárquica gigantesca, onde alunos e professores são submetidos a papéis puramente sociais - fora a discussão de convívios sociais -, onde está a crítica ao pensamento? Como pensar formação ética, pessoal, libertadora, reflexiva?

Está aqui o caos, usado no sentido de desigualdade social, permeando os discursos sobre/da/na escola brasileira contemporânea. Como enfrentar - e não fugir - de imposições? 
Passemos à análise de uma segunda tirinha:

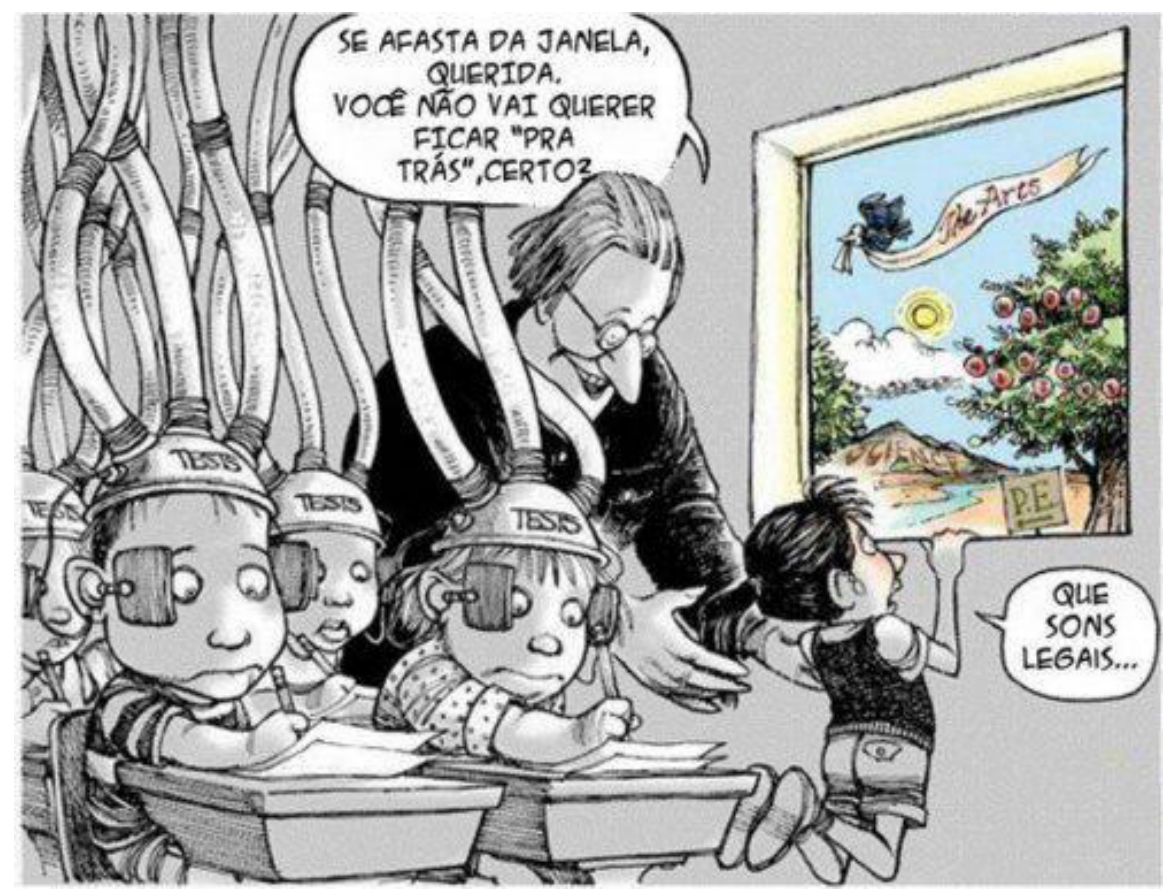

Figura 2: Tirinha retirada do Facebook

Fonte:https://www.facebook.com/photo.php?fbid=104027883133435\&s et=a.104027499800140.1073741830.100005786702879\&type=3\&theater. Acesso em: 3 abr. 2018.

Podemos reconhecer o espaço escolar neste texto? A disposição de pessoas sentadas, enfileiradas, mais novas que alguém que está em pé as direcionando, o enquadramento de uma redoma fechada ao exterior, o lápis, o papel são todos estes elementos da estrutura modelar da escola.

Numa oposição cor x não cor, a tirinha se constrói aludindo a uma crítica do não trabalho pela escola sobre os assuntos que dizem respeito à vida. Em nome de um ideal de sucesso - de futuro - a instauração de um modelo adultocêntrico é imposta aos mais jovens. A isso, podemos inferir que o que diz respeito à criatividade, à inovação, às leituras de mundo está situado no ambiente exterior, no ambiente luminoso, colorido, vívido, dinâmico e, em contrapartida, o caráter mecânico, reprodutor, punitivo, valorativo, excludente se situam no ambiente em que os sujeitos estão, na esfera pedagógica do conhecimento. 
O mundo dos alunos é o de verdades velhas, fabricadas por interesse, de seus antepassados, que eles devem absorver às suas vidas: há pessoas subordinadas, o lugar destas é um específico, não há o que contestar, precisam se contentar.

A tentativa da menina da cena de olhar pela janela, como se um chamamento - 'sons legais' - da vida para ser vivida a convidasse, é argumentada pelo adulto, imagem construída numa espécie de forma grotesca, num tom proximal, doce - "querida" - que lhe propõe afastarse da janela, de distanciar-se do mundo fora, para que ela não fique "pra trás". Ficar para trás revela a ideologia neoliberal instaurada no ambiente escolar, capaz de separar, pautada numa constante série de provas, as pessoas - massa contínua, homogênea - em winners e losers, em merecedores ou não do sucesso de cada um: sucesso aqui é simples: meritocracia capitalista: tem dinheiro aquele que se esforça, aquele que produz, produz e produz, aquele que é empreendedor.

Vemos por esse enunciado - tanto o proferido pelo(a) professor(a) - (?) - quanto o da cena englobante - seu projeto político de dizer: silenciamento e ordem. Num discurso da vida idealista que não toma o acontecimento como base de atuação e em nome de uma manutenção da ordem neoliberal vinculada à globalização e hegemonia de um pensamento único este modelo de escola faz da escola, discursivamente, uma instituição 'tábua de salvação' (GERALDI, 2010). Associada à salvação há a culpa. A escola tem levado a culpa pelo fracasso escolar mediante as exigências imbuídas pela dinâmica mercadológica. Assim, as políticas educacionais ficadas no neoliberalismo tomam como padrão parâmetros de conteúdos a serem ensinados e avalizados posteriormente em testes locais e internacionais, constituindo uma espécie de "educação bancária" - como Paulo Freire (1975) já havia exposto - que produz resultados de hierarquização de instituições de ensino, apontando quais redes (cor)respondem ao 'mercado consumidor'. Como pensar em formação pessoal que valorize os espaços subjetivos e intersubjetivos pela reflexão, como pensar em caráter propedêutico ao Ensino Superior perante esta logística capitalista, idealista e estabilizadora dos momentos aula da Escola Básica?

Este estereótipo de insucesso escolar toma por base questões sociais que um amplo quadro de instituições educacionais brasileiras vem mostrando: o isolamento das crianças em nome de um afastamento das ruas, já que estas representam os problemas à sociedade. Perguntase: por que dicotomizar vida na escola e vida fora da escola? A escola é 
pra vida, mas não dialoga sobre a vida. Então seria o espaço da escola cuidar da violência ligada às famílias, cuidar dos casos de saúde pública, cuidar da alimentação de cada um...? E o cuidado com a reflexão, o pensamento também entram nos objetivos das escolas? Cabe, enfim, tomar um diálogo-dialético com as questões políticas. Mais do que nunca o posicionamento político de cada sujeito é a luta contra o esvaziamento crítico, funcional e formacional da instituição escola. Idealismo não! Planejamento político-social perante a história de cada sujeito envolvido na construção de si e do(s) outro(s).

Mendonça (2001), em artigo "Língua e Ensino: políticas de fechamento", aborda sobre o modo como as políticas de fechamento vão de encontro à noção de heterogeneidade e de imprevisibilidade do discurso, uma vez que estas, segundo a analista, se convergem em três mecanismos de controles de base foucaultiana: a disciplinarização, o sistema de apropriação de conhecimento e a sociedade do discurso. $\mathrm{O}$ estudo mostra que as políticas de fechamento promovem um silenciamento das inúmeras possibilidades de sentidos de textos, uma estereotipação classificatória dos gêneros discursivos e um apagamento das variedades linguísticas não privilegiadas. Aquilo que se tomaria como lugar fluido dialógico numa ciência, tendo no processo de contrapalavra um projeto de dizer, é ressignificado pela instituição escola como estruturação padronizada a ser compreendida como reprodução, dando um fechamento à propriedade responsiva e, por que não, responsável dos discursos. Assim, o enrijecimento conceitual operaria como política fundante das práticas discursivas nas instituições escola.

\section{CONCLUSÃO}

O que se tentou fazer nestes momentos foi uma dialética históricofilosófica a respeito da ideia da transição do foco da racionalidade suprema a um vislumbramento de ações dentro da ideia da instabilidade dos acontecimentos, partindo dos apontamentos abordados pelo linguista João Wanderley Geraldi em seu artigo "Depois do 'show', como encontrar encantamento?".

Tomar estas esferas em jogos dialético-dialógicos nos proporciona investigar e instabilizar nossos entendimentos e nossas práticas contemporâneas. Como pensar formação escolar histórico-científicosubjetiva no espaço atual?

Por traz deste foco dialógico-argumentativo que estamos levando, a leitura de mundo exposta aqui é a tese de uma indeterminação original 
do homem e, consequentemente, uma indeterminação da linguagem e das línguas que o colocam "para a ação, para o movimento, para o diferente, para o outro (animado ou inanimado) na busca de definição de si próprio" (REZENDE, 2011, 708). Sendo assim, aquilo e aquele que é o outro, o diferente, que se opõe, é constitutivo dessa organização. É por meio de constantes embates de si e com o outro (internos e externos), na atividade dos sujeitos que os caminhos da estabilidade vão sendo construídos, em ações de montagem e desmontagem de arranjos, significados ou valores nas operações, metodologias e conclusões provisórias.

Se para Kant, a razão que se movimenta no seu âmbito, nos seus limites, faz o homem compreender-se a si mesmo e o dispõe para a libertação, para Nietzsche, esta autonomia se trata de uma libertação escravizada pela razão, que só faz apertar-lhe os grilhões, enclaustrando a vida humana digna e livre. De certo é que a razão pura não dá conta do tamanho do humano.

Refletido na escola, o modelo idealista predominante na matriz cultural letrada se materializa em discursos que silenciam vozes, rejeitam as vivências dos sujeitos.

A quebra de um processo e de um modelo idealista que fundamentaram questões contribuintes para uma constituição de uma sociedade excludente e desigual a partir da abordagem do CAOS como momento fértil a novas relações de conhecimento e saber torna os processos educacionais um lugar de exploração de si, desviando o paradigma do erro pecaminoso e enaltecendo as práticas humanas do formar-se a cada instante.

Essa perspectiva indaga e traz à tona a construção/o inacabamento permanente do sujeito, ou melhor, do vir-a-ser da condição do homem no mundo (FREITAS et al., 2007). "Quando os futuros são incertos, porque não seguem uma lei ou uma ordem, todas as possibilidades são imagináveis. Abramos os braços para os abraços desta nova aprendizagem" (GERALDI, 2003, p. 260). A pergunta "o que nos resta?" é respondida com "retornar às perguntas"! O que nos resta é perguntar! Este ato requer que concebamos os textos como fluxo de alteridades, com perspectivas de futuro, com projetos de dizer sobre o mundo que podemos abrir em cada texto que nos é chegado.

\section{REFERÊNCIAS}

BAKHTIN, Mikhail; VOLOSHINOV. Marxismo e Filosofia da Linguagem. 6. ed. São Paulo: Hucitec, 1992. 
Estética da criação verbal. São Paulo: Martins Fontes, 2003.

BRAIT, Beth Ironia em perspectiva polifônica. Campinas, São Paulo: Unicamp, 1996. Mikhail Bakhtin: o discurso na vida e o discurso na arte. In: DIETZSCH, M. J.

(Org.) Espaços da linguagem na educação. São Paulo: Humanitas, 1999, p. 11-39.

CHAUI, Marilena. Iniciação à filosofia. São Paulo: Ática, 2010.

EMERSON, Caryl. Palavra exterior e fala interior: Bakhtin, Vygotsky e a internalização da linguagem. In: RIBEIRO, A. P. G.; SACRAMENTO, I. (Orgs.). Mikahil Bakhtin: linguagem cultura e mídia. São Carlos: Pedro \& João Editores, 2010, p. 65-92.

FOUCAULT, Michel. História da Sexualidade I: a vontade de saber. Rio de Janeiro: Edições Graal, 1988.

FREIRE, Paulo. Pedagogia do oprimido. 3. ed. Rio de Janeiro: Paz e Terra, 1975.

FREITAS, M. T.; SOUZA, S. J. e; KRAMER, S. (orgs.) Ciências humanas e pesquisa: leituras de Mikhail Bakhtin. 2.ed. São Paulo: Cortez, 2007.

GERALDI, João Wanderley. Depois do 'show', como encontrar encantamento? Cadernos de Estudos Linguísticos. Campinas, (44): 251-261, Jan./Jun. 2003.

A aula como acontecimento. Aveiro: Universidade de Aveiro, 2004.

A aula como acontecimento. São Carlos: Pedro \& João Editores, 2010.

GRANGER, Giles Gaston. Lógica e filosofia das ciências. São Paulo: Melhoramentos, 1955.

NIETZSCHE, Friedrich. A gaia ciência. Curitiba: Hemus, 2002.

MARCHEZAN, Renata Coelho. Afinidades eletivas: O texto e o discurso. Cadernos de Semiótica Aplicada (CASA), Vol. 6.n.2, dezembro de 2008.

MENDONÇA, Marina Célia. Língua e ensino: políticas de fechamento. In: MUSSALIN, Fernanda e BENTES, Anna Christina. Introdução à Linguística: domínios e fronteiras. (v.2). São Paulo: Cortez, 2001, p 233-264.

RAJAGOPALAN, Kanavillil. Prefácio. In: CORACINI, Maria José Rodrigues Faria. Um fazer persuasivo: o discurso subjetivo da ciência. Campinas: Pontes, 1991.

REZENDE, Letícia Marcondes. A indeterminação da linguagem e o conceito de atividade no ensino de língua materna. In: ESTUDOS LINGUÍSTICOS, São Paulo, 40 (2): p. 707 714, mai-ago 2011.

SANTOS, Jair Ferreira dos. O que é pós-moderno. São Paulo: Brasiliense, Coleção Primeiros Passos, 2005.

Recebido em: 20/04/2020

Aceite em: 15/06/2020 